\title{
Knowledge Energy, Recurrent Learning and the Transformation of an R\&D Institution in a Mexican Public University
}

\author{
Luis Roberto Vega-González (Corresponding author) \\ Instituto de Ciencias Aplicadas y Tecnología, Universidad Nacional Autónoma de México, \\ Circuito Exterior S/N, Ciudad Universitaria, A.P. 70-186, Delegación Coyoacán, CP 04510, \\ Ciudad de México, México. E-mail:1rvg@unam.mx \\ Rodolfo Zanella \\ Instituto de Ciencias Aplicadas y Tecnología, Universidad Nacional Autónoma de México, \\ Circuito Exterior S/N, Ciudad Universitaria, A.P. 70-186, Delegación Coyoacán, CP 04510, \\ Ciudad de México, México \\ Neil C. Bruce \\ Instituto de Ciencias Aplicadas y Tecnología, Universidad Nacional Autónoma de México, \\ Circuito Exterior S/N, Ciudad Universitaria, A.P. 70-186, Delegación Coyoacán, CP 04510, \\ Ciudad de México, México
}

Received: September 10, 2018 Accepted: November 7, 2018 Published: November 23, 2018 doi:10.5296/csbm.v5i2.13628 URL: http://dx.doi.org/10.5296/csbm.v5i2.13628

\begin{abstract}
When University R\&D institutions perform projects to create technology solutions, they produce knowledge and learn. The basic idea proposed in this article is that one of the fuels that produce such a dynamic process is the organization's knowledge energy. When it flows in multidisciplinary projects within and outside an organization's borders, it also produces recurrent learning along each technology prototype improvement. Through the years this dynamic is capable of producing substantial transformations and empower R\&D institutions, as we found in the transformation of the Applied Sciences and Technological Development Center into the Applied Sciences and Technology Institute of the National Autonomous University in México. This is a limited case study.
\end{abstract}

Keywords: knowledge energy, recurrent learning, R\&D Mexican institutions transformation. 


\section{Introduction}

\subsection{Energy, an Elusive Meta-Concept That Fuels Economy}

Heraclitus of Ephesus $~ 500$ BC, pre-Socratic Greek Philosopher, with his phrase "no man ever steps in the same river twice", stated that ever-present change was the fundamental essence of the universe. The movement domain extended beyond our perception because there were imperceptible movements that expose everything existing to constant destruction and renovation (Alinovi, 2007, pp. 26, 29). About 100 years later, Aristotle ( 400 BC) proposed that the reason for anything existing could be attributed to some cause. This postulate is known as the causality principle. Thus, following the basic Greek Philosophers ideas, it seems that there must be a mysterious "entity" behind everything moving and transforming. Nowadays we call it energy.

The word energy is a technical term invented by Thomas Young (1773 - 1829) in 1807, who used it as a convenient abbreviation for the sum of kinetic energy and gravitational potential energy of a mass and the elastic energy of a spring to which the mass may be attached. (Müller, 2007)

From a material point of view, energy is indefinable, since we cannot touch it, or define its color, or revise its constitution (Oviedo-Salazar, 2015). So, in general terms, defining energy is difficult because it is subtle, delicate, and in a certain way a mysterious concept. Anyway, regardless of the way in which we define it, without energy we would not exist nor would the universe exist. Precisely for this reason, dealing with energy is almost an impossible task because in principle, everything, absolutely everything, has to do with it (Sánchez, 2012)

So, energy is one of the more unifying concepts that underlie all natural and social phenomena. (Tagueña \& Martínez, 2000). Energy is movement, is work, and is life. It surrounds us and exists in many forms, continuously transforms from one form to another, it is found in all spaces, makes the sun shine, the earth rotate, the plants grow, people move and our civilizations develop. Also, its stability and good use foster the quality of life of human communities.

For González Arias (2006), the energy word has two meanings, a popular and a scientific one. In the popular discourse it has an intuitive notion, we say that a person is energetic if she is very active. It is in Physics where the scientific meaning of energy is defined.

In the field of physical systems, the energy concept refers to an entity capable of performing work. Work is produced when a force mobilizes a body and releases the potential energy of it. Then, work is energy in transit which means that energy has an inherent characteristic, it can be transmitted. For Ogata (1978), "force is considered a measure of effort, and work is a measure of this accomplishment while energy is the ability to do work. When a time factor is considered, the concept of power appears. In that sense, power is work per unit time". Clearly, an immersed concept is the movement. What moves in the physical world? Machines, objects, particles, ions, electrical charges and so. The movement of the universe and life require energy. Another example in the field of Physics is electricity; the application of a voltage source through a circuit to an incandescent load is able to produce light, when there is a 
current flow. Moreover, energy and mass relate to each other through the square of the speed of light (Einstein, 2005, first published 1905).

But we can also think that energy is able to drive the world economy and transform societies, then it takes the form of a Meta concept because energy is a concept that goes beyond Physics. Besides, for Pacheco-Flores and Melo-Poveda, (2015) it represents the process of wealth creation and has a close relationship with social progress.

Analogously, as energy is related to the concept of force in physical systems, it can be related to the concept of knowledge in organizational social systems. For Foster (2011), knowledge is something that is not easy to define or measure and there has been a tendency to view it as a commodity with unusual characteristics.

Recently Vega-González (2017) proposed that on a macro-economic scale, disruptive innovations act as the fuel of the world economy reactor that during different periods in history, have triggered hundreds of non-disruptive innovations which in turn have been transformed into products for many applications and later diffused into the market. In correspondence to this analogy, the knowledge used to create the disruptive and the non-disruptive innovations through applied research and new product development, eventually takes the form of circulating money that accelerates the growth of the world economy.

\section{Literature Review}

\subsection{Analog Energy Concepts}

Now let's find analogous figures of Physical Systems in the field of research and development (R\&D). In first place it is obvious that not in all but in most cases, innovations require previous intensive $R \& D$. In that regard, $R \& D$ academic teams can be seen as intensive knowledge generation work teams. Therefore, we can postulate that R\&D public and private institutions are organizations where knowledge energy circulates. In that context, Drucker (1998) proposed that knowledge management of R\&D teams can enhance creativity and competitiveness.

The knowledge energy concept as the driving force behind the formation of an autonomous knowledge flow network was proposed by Zhuge et al., (2007), they also pointed out that a primary activity of knowledge management is the monitoring of the knowledge energy of nodes, which permits the evaluation and adjustment of knowledge flows, leading to the selection of appropriate strategies such as the consideration of the efficiency and efficacy of knowledge sharing and the routing of knowledge in a geographically distributed team.

Zhuge et al., (2007, pp. 268), also proposed some analogies between knowledge generation systems and physical systems. Among others, they noted that potential energy occurs in a number of systems. Two classic examples are that hydraulic pressure causes water to flow along a river or through pipes, and voltage causes electrical energy to flow through wires. Similarly, they proposed the idea of knowledge energy causing additional new knowledge.

Foster (2014, p. 214) proposed that we have to acknowledge the thermodynamic character of 
all economic systems in which there must exist an 'energy gradient' which can be drawn upon to allow a system to do work. For a long time in human history, a large proportion of the population did mainly physical work, fuelled by a food energy gradient. However, humans in modern times have devised capital goods to do physical work using flows of non-human energy. Today, work is only minimally physical in nature where classic Industrial economy activities based on 'machine operator' have been transformed into knowledge economy based on the 'knowledge worker'. This trend seems to be the current and medium-term norm.

\subsection{The Concept of Social Energy}

As we have seen, energy is a nonexclusive entity for physical systems, society also produces and handles different types of energy. The theory of Grey Systems and its application is intended to bridge the gap existing between social science and natural science (Julong, 1989). The concept of social energy was pioneered by Julong (2007) who proposed the following basic definition: the energy that emerges from actions of social groups and contributes to the progress of human society is referred to as social energy. This applies to all economy sectors and knowledge fields. Even fashion has been studied by Esculapio (2016) as a source of social energy.

Julong also stated that there are social energies within a variety of social groups, which influence in different degrees the processes of management, decision-making and resource allocation. Such energies play an important role in Grey management science.

But, what about the field of socio-economic systems where organizations play a substantial role? In first place, these systems are complex, since they are composed of an incommensurable number of elements and state variables with either dependent or independent relationships among them, which makes them difficult to analyze (Miller and Page, 2007).

Socio economic systems belong to the category of Unascertained Systems where the fundamental characteristic is the incompleteness and inadequacy in their information. The information about the elements (parameters) is incomplete. The information about the structure of the system is incomplete. The information about the boundary of the system is incomplete; and the information on the system's behaviors is incomplete (Liu \& Lin, 2010). The focus of grey systems theory is on uncertainty problems with small samples and poor information that are difficult for probability to handle (Liu et al., 2013).

In that regard, new complex systems theories indicate that a good way to understand this kind of systems is the use of analogies with biological, chemical or physical systems. Moreover, as is well known, societies always have problems in the fields of health, education, security, food supply, water, sustainable energy sources, and so on. To solve them, the different social sectors in the macro socio-economic system need to create new knowledge for the development of innovative technology.

This dynamic creates devices, technology, products and money that when diffused in the market drives the movement of society and consequently of the economy variables. Thus, it seems that the flow of knowledge energy coming from people to the organizations and 
society, is in certain ways a fuel that makes society move. In other words, knowledge generation processes provide the knowledge energy that society needs to fulfill its needs. This phenomenon works in a similar way to fossil fuels, bio-fuels and others which provide the energy to produce work and movement in the physical world. Similarly, the concept of power can be understood as the capability of an organization or a whole society to overcome its problems providing their members with the elements to have a healthy and happy life within a time period, of a year, a decade, or a Century.

At the end of the 17th century Lavoisier said that energy is not created nor destroyed, it only transforms; also, the creation of biological or physical energy requires the consumption of natural resources as a primary source of energy. For example, biological cell plants need water, nitrogen, calcium and other nutrients for the creation of healthy vegetables; on the other hand, vehicle motors need fossil fuels or bio-fuels to work, and electrical motors need electricity to operate. Therefore, the production of energy needs to be carried out properly and efficiently to avoid wasting resources and raw materials.

Moreover, physical energy can be dangerous if it is not handled safely. In the same way, the energy of knowledge possessed by an organization must be controlled properly to produce innovative technology improving the organization's work efficiency and fostering its competitiveness. In this way, knowledge energy can be recognized as a kind of fuel that drives core organizational processes enabling organizations to reach their goals. Naturally, organizations and firms that do not produce or use knowledge, are undoubtedly destined for disappearance.

The purpose of this work is to analyze the way a public Mexican R\&D university entity participates as a knowledge energy source that promotes the dynamics and movement of society at a certain level. The knowledge required at the university to create technological solutions is not created spontaneously; it requires a link between university and society organizations and the organizational adjustment and learning that comes when the participants develop innovation projects. To make all this possible, the application of knowledge management is required during the whole process.

\section{Theoretical Framework}

\subsection{Organizational Learning and Knowledge Spiral}

The processes of research, development and innovation $(R \& D+i)$ require the integration of the efforts of different individuals and groups of the organization. Frequently, this is done through the combination of knowledge, skills and individual attitudes that lead to improvement of the capabilities of the organization.

New knowledge can be created in both academic and industrial activities through scientific research, and technology and product development. This is optimal when the creation of new products takes into account both the needs of the market and the potential of satisfying those needs efficiently using the scientific and technological knowledge that is already part of the public domain. 
In order to carry out the $R \& D+i$ processes looking to fulfill the objectives and goals of the organization, it is necessary that industries and institutions have the capacity to organize work teams of highly qualified personnel that dominate diverse disciplines, as well as technical, support and project management personnel participate.

When organizations work in this way, a dynamic that allows the feedback of each individual contribution is created, enriching the organization. Simultaneously each of the members of the work groups learns from the experience accumulated in the organization. This positive feedback environment produces a kind of energy ideal for the creation of knowledge. Then, in any organization we can identify two parallel development paths that communicate and enrich each other, on one hand the academic, professional or technical experts who master different disciplines and work in different areas of development to enrich their own knowledge; while on the other hand, they also develop new skills and change their attitudes towards themselves and to the organization they serve.

Also, when it is required, organizations can hire human resources having knowledge and skills that don't exist within the organization, modifying its organizational structure to optimize its operation and completely attain its goals. The flexibility of an organization is essential to enhance its efficiency and its orderly development according to the institutional plans. Insofar as a firm or an institution seeks to incorporate more qualified people, the possibility of developing new competences grows. Likewise, as people are incorporated into more structured and orderly organizations, they will enrich their personal knowledge for their own development, and consequently, individual skills contribute significantly to strengthening institutional competencies. Therefore, when these processes happen within the organization, we can conclude that personal learning contributes to organizational learning.

According to Nonaka and Takeuchi (1999), there are different knowledge types, as shown in Table 1. Tacit knowledge is created "here and now" in a specific practical context. This knowledge type is transmitted between individuals through communication, it is an analog process that requires simultaneous processing of the complex themes shared. Nearly always, tacit knowledge requires empirical learning.

Explicit knowledge is one that has already been assimilated by individuals or organizations through experience and that can be materialized in manuals, reports, construction drawings or books.

Nonaka and Konno (1998) have proposed that there are four ways of conversion of tacit and explicit knowledge: 1 . from tacit to tacit, which is called socialization; 2 . from tacit to explicit or exteriorization; 3. from explicit to explicit or combination; 4. from explicit to tacit or internalizing. 
Table 1. Knowledge types (Nonaka and Takeuchi, 1999, p. 61)

Tacit Knowledge (subjective)

Experienced Knowledge (body)

Simultaneous knowledge

(here and now)

Analog knowledge (practical)
Explicit Knowledge (objective)

Rational knowledge (mind)

Sequential knowledge

(there and then)

Digital knowledge (theory)

Socialization is a process consisting of generously sharing old and new experiences. An individual can acquire tacit knowledge by directly observing others, without speaking. Therefore, the creation of tacit knowledge happens when knowledge and technical skills are transmitted between teacher and trainee and also when mental models are shared. Socialization also occurs between those who develop products and their clients. In the public or private $R \& D$ organizations, the interaction of research and technical people with clients during the development of a product and even after its introduction to market is a non-ending process that allows a build-up of tacit knowledge and improves the creation of ideas. Nevertheless, according to Parboteeah et al., (2016) there is a risk of losing knowledge within an organization that occurs when an employee leaves, taking all knowledge with him. Therefore, a strategy needs to be implemented to ensure that knowledge remains within the team.

Exteriorization is a process through which tacit knowledge is translated in the form of explicit concepts. It is in essence a knowledge creation process, in which tacit knowledge becomes explicit and adopts the form of metaphors, analogies, concepts, hypothesis or models. The exteriorization is generated by dialog and collective discussion.

Combination occurs between organization departments or groups with the use, production and intensification of explicit knowledge to produce new knowledge of the same type; therefore, it is a process of systematization of concepts in which a knowledge system is generated. Individuals interchange, combine and create knowledge through education and formal training given in schools and using different media such as documents, meetings, telephone conversations or computerized communication networks. At the highest levels of management of an organization, combination is performed when the basic concepts such as product concepts, are combined with big concepts, such as the corporate vision, and are integrated to give a new meaning.

Internalization is a conversion process that transforms explicit knowledge to tacit knowledge. It is closely related to "learning by doing". When organizations internalize experiences based on the tacit knowledge of individuals, through socialization, exteriorization and combination, results are shared mental models and technical know-how. 


\section{Al Macrothink}

The creation of organizational knowledge is a continuous interaction of tacit and explicit knowledge. The knowledge spiral begins with the socialization of organizational members who cultivate different disciplines, usually beginning with the creation of a field of interaction. This field allows team members to share their experiences and mental models. Immediately, the exteriorization begins, with collective dialog or meaningful reflection in which the use of a metaphor or appropriate analogy can help members to articulate hidden tacit knowledge that is otherwise difficult to communicate. Later, combination begins with the distribution of new knowledge through networks and other organization sections, culminating with the shaping of a new product, service or administrative system. Finally, internalization occurs through learning by doing.

The role of the organization in the process of knowledge creation is to provide the proper context to facilitate group activities and the creation and accumulation of knowledge at the individual level.

The Knowledge spiral is driven by the organizational intention of achieving goals. Today, knowledge management pursues this. In the field of business all this requires a strategy. From the point of view of the creation of organizational knowledge, the essence of the strategy is to develop organizational capacity to acquire, create, accumulate and exploit knowledge. As can be seen in Figure 1, Nonaka and Konno (1998, op cit) in their model show that organizational knowledge generation is a circular process that becomes a growing spiral as time passes. It begins with the socialization of the tacit knowledge of individuals; then is externalized and becomes explicit in the different groups of the organization.

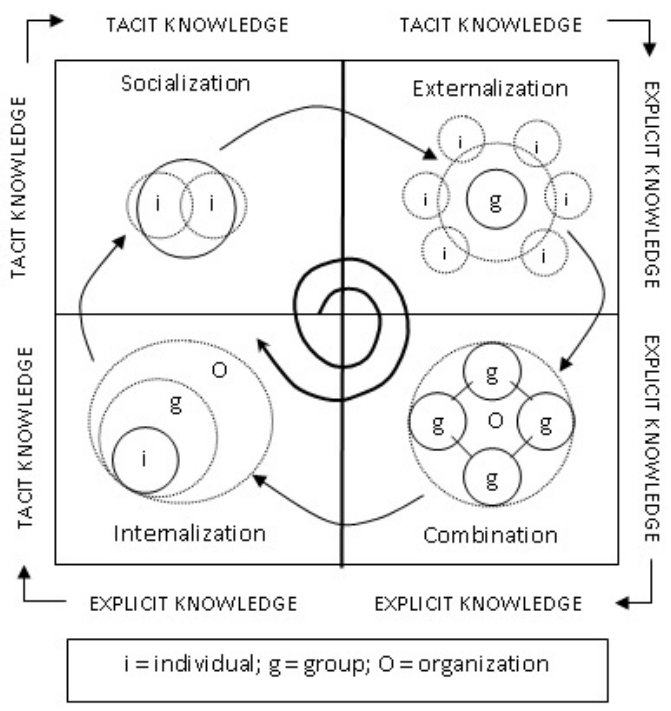

Figure 1. Spiral of the evolution of knowledge conversion and self-transcending process Source: Nonaka and Konno (1998). 
Subsequently the group's explicit knowledge is combined among the different groups or departments of the organization. The cycle is closed when knowledge is internalized in the organization, becoming new tacit knowledge, but now belonging to the whole organization. In general terms, when the organization develops any kind of projects, learning experiential cycles seem to occur.

\subsection{Management of Knowledge Energy}

Figure 2 is a representation of the flow of knowledge energy that is normally created in the $\mathrm{R} \& \mathrm{D}+\mathrm{i}$ projects developed at universities.

Everything begins with the linking actions carried out between university and the external public or private organizations to sign agreements for project development. The parts that normally sign the collaboration agreements are members of the organization that requires the technological solution, the institution that provides financing, the university entity that will perform the R\&D and sometimes other stakeholders.

At the center of Figure 2 it can be seen that different $R \& D+i$ projects agreed with organizations of some economic sectors in society could be active at the same time, producing a kind of continuous flow of knowledge energy with an inherent dynamic. The media required for the flow of Knowledge Energy in an R\&D institution is its employed people, such as researchers, academics, technicians, operators and back-up people, among many others. Therefore, it can be understood as a kind of social energy.

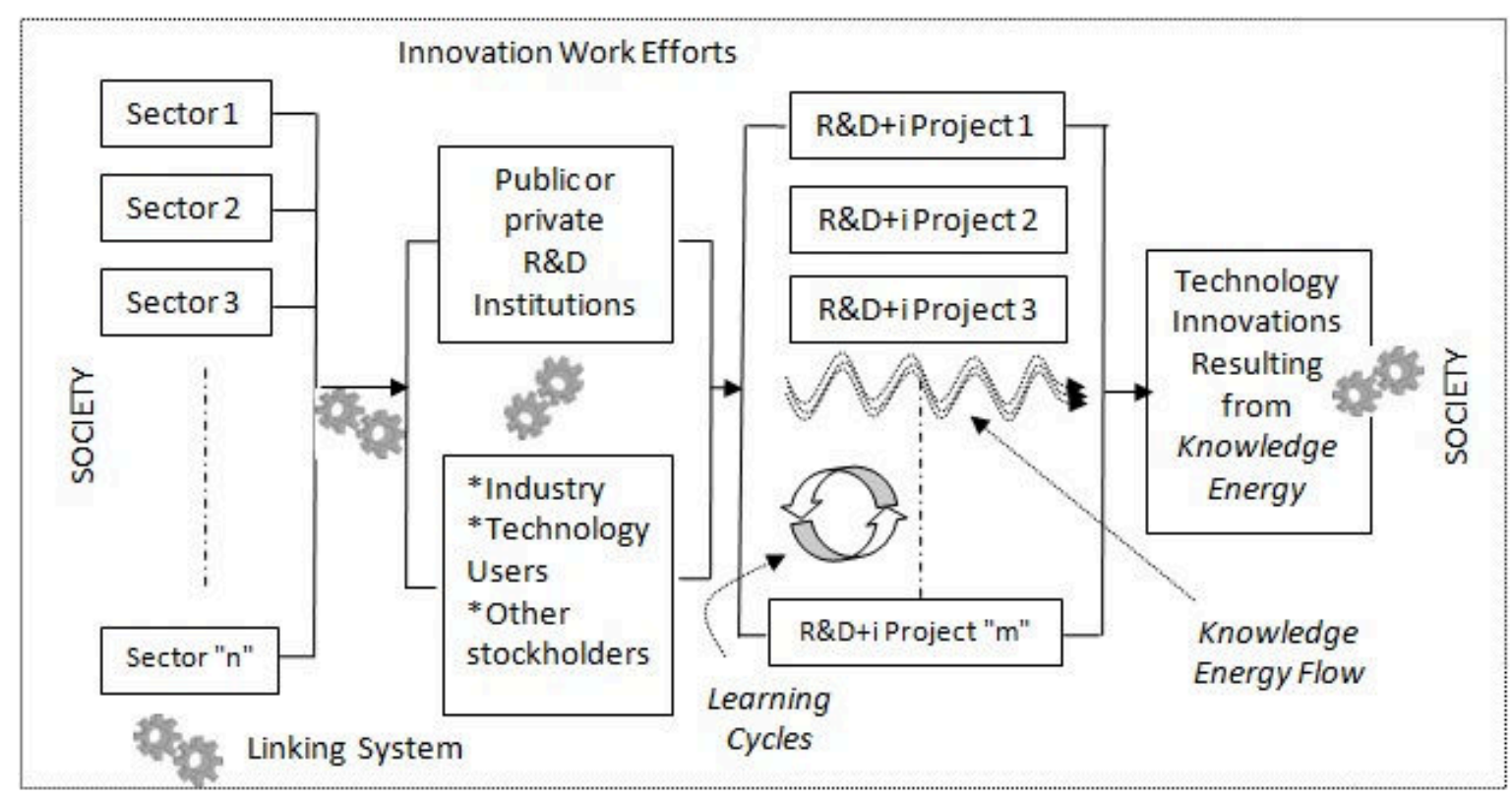

Figure 2. Flow diagram of the knowledge energy that occurs in the university-society relationship

Source: developed by authors based on studies. 
Naturally, to be optimized, energy needs to be controlled and managed. The basic process used to handle knowledge energy is known as Knowledge Management (KM). Chen \& Mohamed (2007), state that knowledge management is a process that focuses on knowledge-related activities to facilitate knowledge creation, capture, transformation and use, with the ultimate aim of leveraging organizations' intellectual capital to achieve organizational objectives. Knowledge Management is the process of identifying, acquiring, using, and creating data, information, and knowledge, with internal and external organizational relevance, to improve both efficiency and effectiveness of the organization, and ensure permanence in the competitive scenario.

Also, according to Groff \& Jones, (2012), Knowledge Management (KM) refers to a set of organizational activities to achieve organizational objectives by making the best use of knowledge. Specifically, capturing, sharing, and applying are Knowledge Management processes that can support other organizational processes involving collective and individual learning in university research groups. (Paez-Logreira et al., 2016, Op. Cit.) Also, Parboteeah et al., (2016) proposed models for including the risk of knowledge sharing and knowledge loss in the KM process.

Thus, we can consider that the organizational learning in an institution that performs $R \& D$, is a process that requires social energy and depends on the size of the group that interacts and on its homogeneity (Mayhew et al., 1995). According to Lewis (2012), another important variable is the predisposition of the members of the organization groups to interact, and this can be studied with social energy theories of segregation and socialization. Therefore, organizational learning depends on the social process of tacit to explicit knowledge conversion and vice versa, and clearly it is not a process confined to an individual. Therefore, the authorities who perform Knowledge Management in an R\&D organization must pursue and stimulate the communication between the members of the academic groups that perform the $R \& D+i$ projects and the external organization members who contract or are part of the collaboration projects.

\section{The Production and Flow of Knowledge Energy at R\&D Organizations}

The spiral of knowledge conversion in an organization that performs $\mathrm{R} \& \mathrm{D}+\mathrm{i}$ projects occurs in several stages. Sometimes after development work begins, the first technology results are obtained and then gradually improved. Stating the basic idea that applied research and technological development activities are knowledge generators, we propose that as in a virtuous phenomenon, when knowledge conversion occurs, tangible technology results emerge, and knowledge is created, producing recurrent learning within the organization. Each one of the R\&D organization members has its own tacit knowledge level that depends on the discipline they dominate.

This knowledge is combined with the one possessed by other investigators, academics and technicians and is later exteriorized in the form of prototypes, technical manuals and scientific articles among other products. This dynamic produces explicit knowledge that, when it is internalized in the organization generates technology know-how that can be disseminated in society. Then, the continuous realization of projects produces new knowledge 


\section{Ml Macrothink}

that flows continuously and at the same time new human resources are formed in a virtuous circle. Thus, the capabilities of the organization are built from the previous work of the academic groups, technical people and students. In other words, previous knowledge in combination with the latest results of the people that are performing the actual $\mathrm{R} \& \mathrm{D}+\mathrm{i}$ projects, produce new knowledge. Furthermore, at the end of the knowledge conversion process, knowledge becomes internalized in the organization producing the emergence of critical competencies. This process requires knowledge management, which is a determining factor to plan the organization's future direction (Hafeez et al., 2002). Therefore, practical experience shows that within an R\&D development environment, adequate knowledge management produces recurrent learning, empowering the capabilities of the organization.

\subsection{The Development of Technological Solutions at the ICAT}

The Institute for Applied Science and Technology (ICAT, from Spanish) is part of the Scientific Research Subsystem of the National Autonomous University of Mexico (UNAM, from Spanish). One of ICAT's main objectives has been to establish links with external organizations from different economic and social sectors of the country and develop technology solutions responding to their requests, seeking to apply the knowledge generated to the solution of relevant problems.

The ICAT currently has 117 academic R\&D fellows and about 110 administrative and support personnel. It is a multidisciplinary organization working in diverse fields of knowledge performing projects for the following application areas: health, science and technology education, environment and energy.

In Figure 3 we can see a representation of the technology development that occurs in the $\mathrm{R} \& \mathrm{D}+\mathrm{i}$ innovation projects developed at the ICAT in collaboration with other public or private organizations. The central line indicates the different stages that happen in a typical project.

Stages are clearly defined by the different levels of the technology prototypes obtained. It is important to note that the process takes a long time and requires the investment of important financial resources. If everything functions properly, the funds invested will be recovered when the technological product is launched to market and begins its exploitation through sales and social diffusion. The project begins when the collaboration agreement is signed with a counterpart who requires technology and contributes with economic resources to cover expenses and to buy the required equipment to carry out the development. 


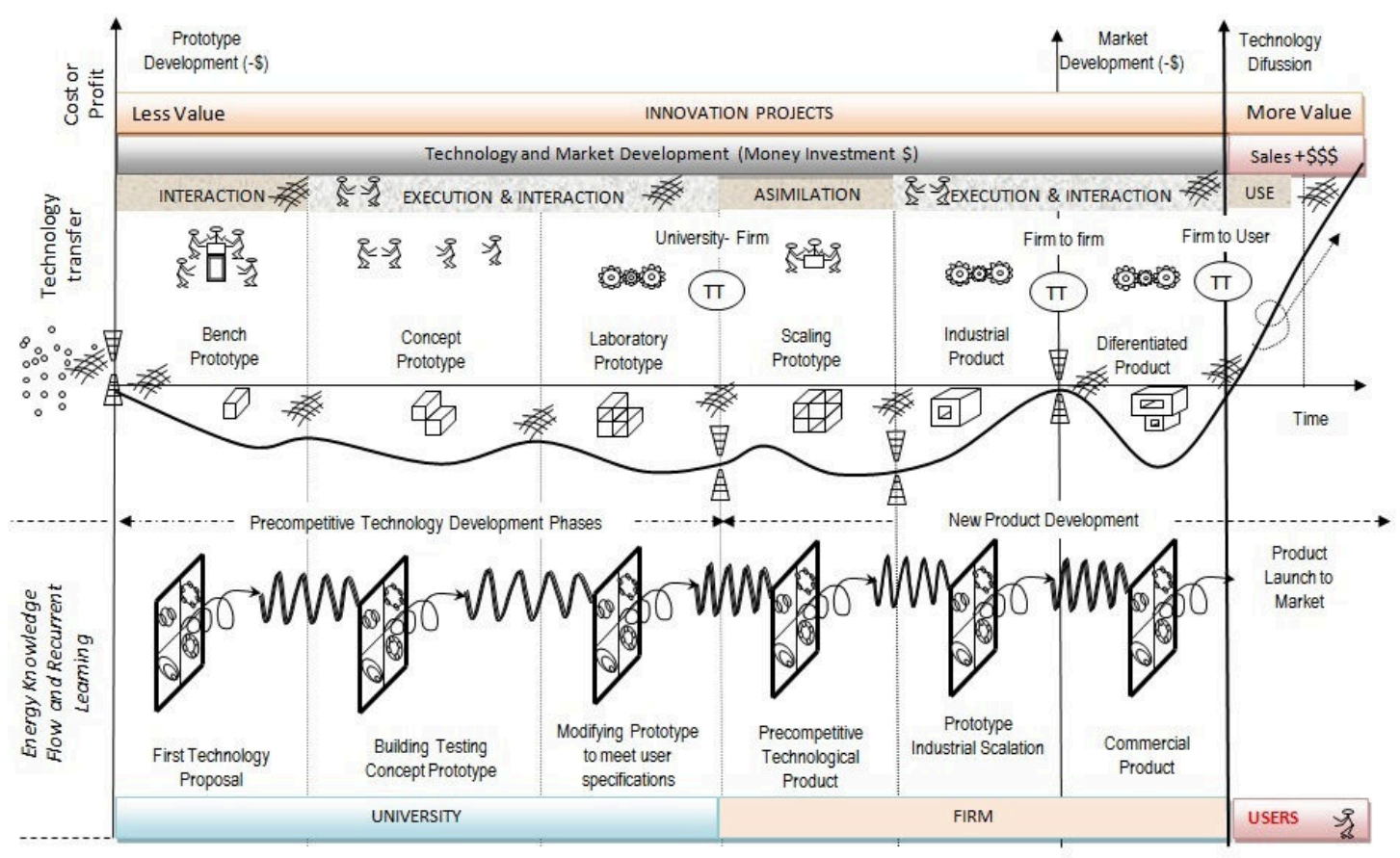

Figure 3. Knowledge Energy Flow and recurrent learning in an $R \& D+i$ project

Source: developed by authors, based on studies.

Nearly always the first result obtained is a bench prototype that, most of the time, is used for the initial demonstrations of size, layout, functional specifications and so; generally speaking, this prototype shows the general idea pursued for the technology. When it is approved, a proof of concept prototype is developed. The main contribution of this stage is the complete functionality test. In other words, this prototype must be functional, complying with all initial specifications. When this is done, and the stakeholders are satisfied, the team continuous its work improving the prototype characteristics to obtain a Laboratory prototype in a more integrated fashion and with a better external appearance. At this level, the prototype can be considered the first version of an integrated technology handcrafted product.

At this project stage, intellectual property strategy and protection work must be performed to obtain property titles to back up the technology transfer agreements between the university and the external organization who financed the work or other interested parties. After the signing of the technology transfer agreement, the technology product is passed to the firm to begin a project to scale the technology from lab level to a precompetitive product. Sometimes, when the physical prototype and its specifications are approved, within the firm a new technology transfer occurs between the R\&D and the industrial development groups. The firm must now evaluate and take the decision to run a new product development project to scale the prototype and improve its functional specifications to the level of an industrial-grade product. At the end of the development line, using information from market 
studies a final project to obtain a differentiated commercial product with appropriate appearance and design must be carried out.

\subsection{The ICAT Projects for the Health Sector}

At the bottom of Figure 3 it can be seen that during the journey between the different stages of a technology development project a continuous flow of knowledge energy and recurrent learning is produced. This learning creation process can even be expanded to the partner organizations who participate in the project. This phenomenon has happened to a greater or lesser degree, in the different knowledge fields cultivated at the ICAT, which are Health, Science and Technology Education, Environment and Energy. Just to illustrate how this phenomenon has occurred, here we review some of the projects that the ICAT has developed for the health sector and the consequences resulting after a few years of this process.

The ICAT has collaborated with many different organizations of the Mexican Federal Health Ministry in order to develop some technology solutions for them. In 2003 using funds coming from the National Science and Technology Council (CONACYT, from Spanish) an electronic multiple cardiac valve tester and a machine for the manufacture of mounting rings for cardiac bio prostheses were developed for the National Cardiology Institute (INC, from Spanish).

In 2004 an automatic laser cutting machine for bovine pericardium was developed to increase the INC valve bio-prostheses production. Later, in 2008 with funds from the Federal District Government Science and Technology Institute (ICYTDF, from Spanish), a system to help radiologists take biopsies to diagnostic mammary cancer was developed, limiting the intervention and the pain suffered by the patient during the procedure. From 2009 to 2012 more than a dozen health projects were financed by the ICYTDF for the ICAT; among them, a thermograph based diagnostic system for diabetic foot and a prostatic surgery teaching system, were developed.

Many academic groups of the institute have participated in the projects developed for the health sector. In particular, the following groups have had intense participation: Electronics (E), Product Engineering Unit (PEU), the biomedical, physical and computational images group, and the micromechanics and mechatronics group (M\&M). By 2018 in addition to the groups mentioned, other academic groups such as the process engineering group, the biomedical sensors group and the image analysis visualization and bioinformatics group joined the process.

When starting the projects, the trigger of the knowledge energy creation process is the socialization occurred when different members of the project discuss and analyze the project specifications and the schedule program. Using the Nonaka \& Konno (1998) knowledge spiral conversion model shown in Figure 2 and taking into account the technology development process shown in Figure 3, in Figure 4, we show how the technology requests from the different health institutions on the left side of the figure, have been transformed into technology solutions that the institute has delivered to specific Health Sector Institutions on the right side of the figure.

As was mentioned above, frequently, several projects are being developed at the same time in 
parallel with different schedules. The result of all this experience is the recurrent learning that becomes interiorized in the individuals, the academic groups and the community of the ICAT.

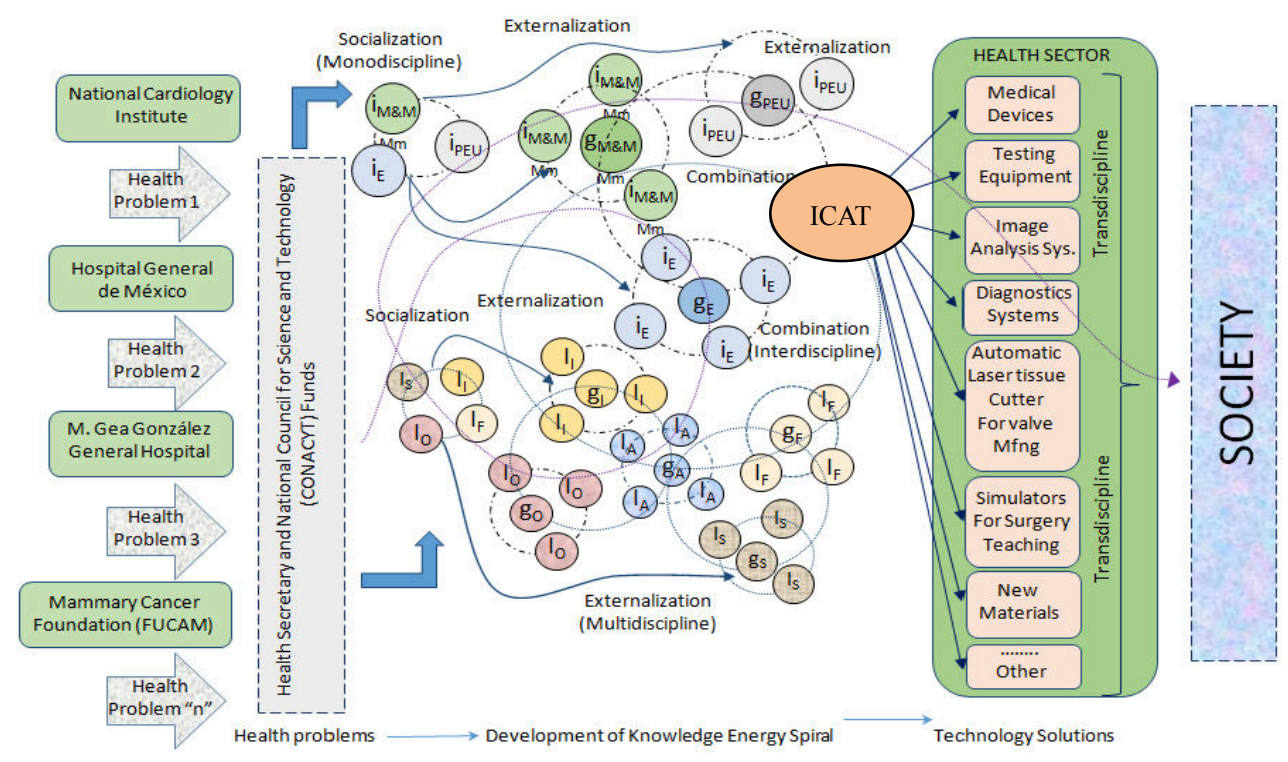

Figure 4. Knowledge Energy is transformed into technology solutions for health problems

Source: developed by authors, based on studies.

Thus, the Knowledge Energy transits through the organization while technology solutions are obtained, and the recurrent learning becomes the stored Knowledge Energy that is retained within the organization.

As can be seen in Figure 5, in the medium term, the dynamics described produce major effects and changes in the organization. Now take a look on the evolution of the organization. The ICAT was created back in 1971 as the Instruments Center (CI, from Spanish) to develop instruments and didactic materials for the University High Schools subsystem.

During the first three decades, the CI passed from being a service and engineering organization to a research and development one. Several laboratories were created, many researchers were hired, and infrastructure and equipment began to grow. By 1999 the CI became part of the UNAM's Research Subsystem. Because of its growth and research activities, in 2002 its named was transformed to Center for Applied Science and Technological Development(CCADET, from Spanish), and its Linking Office was created.

During the first decade of the new CCADET Center, its organization was consolidated hiring more academics and support and administrative people to perform R\&D projects in four departments, one prototypes Section and a Mechanical workshop. 


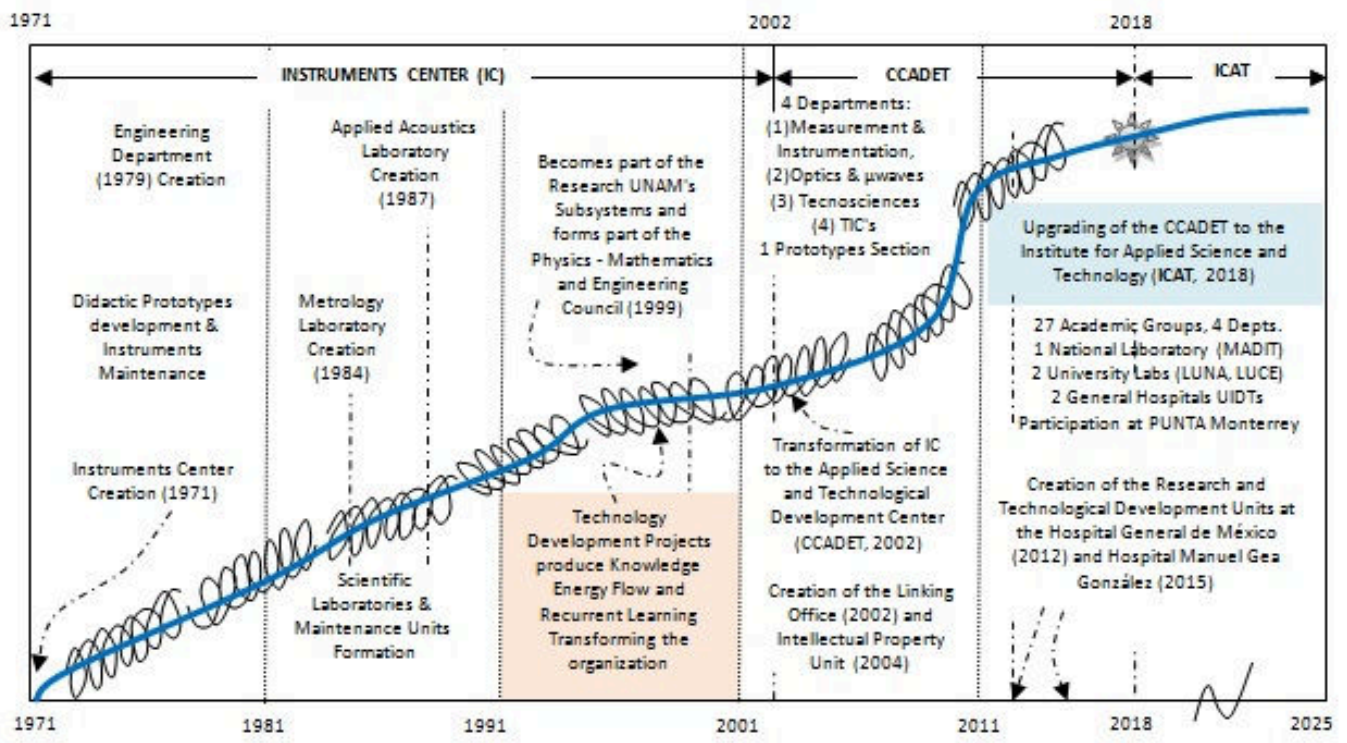

Figure 5. Major Organization Transformations

Source: developed by authors, based on studies.

The organization also included the academic, the technical and the administrative Secretaries. Many projects were performed, and new knowledge developed and the organization continued with its recurrent learning. Soon the dynamics generated by this knowledge Energy produced new transformations.

In 2014 the Micromechanics and Mechatronics (M\&M) group was transformed into the Additive and Digital ManufacturingNational Laboratory (MADIT, from Spanish). Up to 2018, through the signature of three agreements, MADIT received funds from CONACYT for its consolidation which lead to the formation of a network of institutions across the Mexican Republic, mainly devoted to modern additive manufacturing. In 2012, another great transformation took place, the creation of the Research and Development Unit of the CCADET at the Mexico's General Hospital (HGM, from Spanish). The joint work of these new groups has had, in a short time, extraordinary effects in the society. In 2016 a process for the manufacture of skull maxillary implants using additive manufacturing techniques was developed in collaboration with physicians from the HGM.

This project was submitted for approval by academic fellows of the Research and Development Unit of the CCADET to the medical authorities of the HGM. It took some years to develop the technology. Currently the CCADET's skull prostheses have been implanted successfully in several patients of the HGM and the technology has been licensed to a firm for its diffusion and exploitation.

Finally, on the 22nd of March 2018 the UNAM's University Council approved the upgrading of the Center to the category of an R\&D Institute within the Research Subsystem of the UNAM, with the name Institute for Applied Science and Technology(ICAT). 


\section{Conclusion}

From a systemic point of view, an organization evolves and grows, dealing with economic and political factors and needs to develop good relationships with other organizations of different economic sectors of the society. In the case of the current Institute for Applied Science and Technology (ICAT); formerly CCADET until March 2018, many actions must be performed in order to provide technology solutions for their allied organizations in the mid-term. This also will require good leadership, the commitment of its academic people and groups and continuous hard work.

The research and development people have had to learn how to work in teams to perform multidisciplinary and trans-disciplinary projects to surpass and transform individual success into common welfare.

In management literature there is a clear distinction between first- and second order organizational changes (Watzlawick, et. al, 1974). First-order or incremental continuous changes may involve adjustments or improving systems, processes or structures, but do not involve fundamental change in strategy, core values or corporate identity. This kind of change maintains and develops the organization (Newman, 2000). Paradoxically, these changes can be designed to support organizational continuity and order. On the other hand, second-order transformational or discontinuous change means a radical transformation, and fundamentally alters the organization at its core. Second-order change entails not only developing but transforming the nature of the organization.

In this paper we have shown that the dynamics that arise when knowledge energy and recurrent learning occurs continuously through the years in an $R \& D$ organization, can produce extraordinary transformations in it. However, the transformation processes that occurs in living organizations depends, primarily, on the knowledge energy production and the recurrent learning of its research and development academic staff. We have shown that these processes in conjunction with other political, economic and organizational influential variables produced a second-order organizational change such as the transformation of an $R \& D$ Center into an R\&D Institute, giving way to a new and very promising period of applied science and technology development results contributing to the nation's welfare.

The contribution of this paper is that the concepts of knowledge energy and recurrent learning can be used to analyze the practice of technology management of R\&D institutions and understand the processes behind the studied organizations evolution. Since the results of this paper refer to a case study, it will be necessary to design and perform a profound investigation to deduct general implications in organizational change theory.

\section{References}

Alinovi, M. (2007). Historia de la Energía (1st ed.). Capital Intellectual, p. 138.

Chen, L., \& Mohamed, S. (2007). Empirical Approach to Understand the Knowledge Management Process. Accelerating Innovation in Engineering, Management and Technology, $525-532$. 


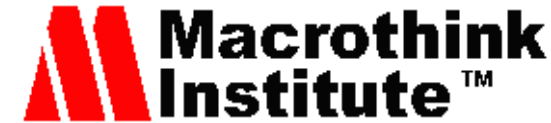

Case Studies in Business and Management ISSN 2333-3324 2018, Vol. 5, No. 2

Drucker, P. F. (1998). Harvard Business Review on Knowledge Management. Boston, MA: Harvard Business School Press.

Einstein, A. (2005). ¿Depende la inercia de un cuerpo de su contenido de energía? Teorema XXIV/2, pp. 12-124. First published in 1905 by Albert Einstein in the German title "Ist die Trägheit eines Körpers von seinem Energieinhalt abhängig?” en la revista Annalen der Physik, 17, 639-641 (1905). Retrieved from file://C:/Users/Gateway/Downloads/Dialnet-DependeLaInerciaDeUnCuerpoDeSuContenido DeEnergia-1255180.pdf

Esculapio, A. (2016). Fashion as social energy, Palazzo Morando- Costume Moda Immagine, Milan. International Journal of Fashion Studies, 3(1), 157-161. https://doi.org/10.1386/infs.3.1.157_7

Foster, J. (2011). Energy, aesthetics and knowledge in complex economic systems. Journal of Economic Behavior \& Organization, 80, 88-100. https://doi.org/10.1016/j.jefo.2011.02.013

Foster, J. (2014). Energy, knowledge and economic growth. Journal of Evolutionary Economics, 24, 209-238. https://doi.org/10.1007/s00191-014-0348-6

González Arias, A. (2006). El concepto "energía \& quot"; en la enseñanza de las ciencias. Revista Iberoamericana De Educación, 38(2), 1-7. Recuperado a partir de https://rieoei.org/RIE/article/view/2660

Groff, T., \& Jones, T. (2012). Introduction to Knowledge Management. Rutledge, p. 183.

Hafeez, K. Y., YanBing, Z., \& Malak, N., (2002). Core Competences for Sustainable Competitive Advantage: a structured methodology for identifying core competence. Engineering Management, 49(1), 28-35. https://doi.org/10.1007/s00191-014-0348-6

Julong, D. (1989). Introduction to Grey System Theory. The Journal of Grey System, 1, 1-24.

Julong, D. (2007). Social System in GMS. The Journal of Grey System, 1, 1-4.

Lewis, V. A. (2012). Social Energy and racial segregation in the university context. Social Science Quarterly, 93(1), 271-290. https://doi.org/10.1111/j.1540-6237.2008.00548.x

Liu, S., \& Lin, Y. (2010). Grey Systems Theory and Applications. Springer-Verlag. https://doi.org/10.1007/978-3-642-16158-2

Liu, S., Forrest, J., \& Yang, Y. (2013). Advances in grey Systems Research. The Journal of Grey System, 25(2), 1-18.

Mayhew, B. H., McPherson, J. M., Rotolo, T., \& Smith-Lovin, L. (1995). Sex and Race Homogeneity in Naturally Occurring Groups. Social Forces, 74, 15-52. https://doi.org/10.1093/sf/74.1.15

Miller, H. J., \& Page, E. S., (2007). Complex Adaptive Systems: an introduction to computational models of social life. Princeton University Press, p. 263.

Müller. (2007). A history of thermodynamics: The doctrine of energy and entropy. Springer. 
Newman, K. L. (2000). Organizational transformation during institutional upheaval. Academy of Management Review, 25(3), 602-619. https://doi.org/10.5465/amr.2000.3363525

Nonaka, I., \& Konno, N. (1998). The concept of "Ba": building a foundation for knowledge creation. California Management Review, 40(3), 40-54. https://doi.org/10.2307/41165942

Nonaka, I., \& Takeuchi, H. (1999). La organización creadora del conocimiento, cómo las compañías japonesas crean la dinámica de la innovación. Ed. Oxford.

Ogata, K. (1978). Systems Dynamics. New Jersey: Prentice Hall, p. 596.

Oviedo-Salazar, J. L., Badii, M. H., Guillen, A., \& Lugo Serrato, O. (2015). Historia y Uso de Energías Renovables. International Journal of Good Conscience, 10(1), 1-18.

Pacheco-Flores, M., \& Melo-Poveda, Y. E. (2015). Recursos naturales y energía. Antecedentes históricos y su papel en la evolución de la sociedad y la teoría económica. Energética, 45, 107-115. Retrieved from http://www.revistas.unal.edu.co/energetica

Paez-Logreira H., Ronald Zamora-Musa, R., \& Velez-Zapata, J. (2016). Relation Analysis of Knowledge Management, Research, and Innovation in University Research Groups. Journal of Technology Management \& Innovation, 11(4), 5-11.

Parboteeah P., Jackson, T., \& Wilkinson, N. (2016). A Theoretically Grounded Model to Reduce the Risk of Knowledge Loss in Organisations: An Energy Company Evaluation. Knowledge and Process Management, 23(3), 171-183.

Sánchez Ron, J. M. (2012). Energía: una historia del progreso y desarrollo de la humanidad. CSIC Ministerio de Economía y Competitividad (Gobierno de España. Lunwerg Eds.), p. 273.

Tagueña, P. J., \& Martínez, F. C. M. (2000). Energy. Revista Digital Universitaria, 1(2). Retrieved from http://www.revista.unam.mx/vol.1/num2/art2/index.html

Vega-González, L. R. (2017). Using patents and innovation strings to anticipate the next Kondratieff long waves. Int. J. Technology Intelligence and Planning, 11(3), 212-229. https://doi.org/10.1504/IJTIP.2017.10006430

Watzlawick, P., Weakland, J., \& Fisch, R. (1974). Change: Principles of Problem Formation and Problem Resolution. New York: W.W. Norton.

Zhuge, H., Weiyu, G., \& Xiang, L. (2007). The potential energy of knowledge flow. Concurrency and Computation: Practice and Experience, 19, 2067-2090. https://doi.org/10.1002/cpe.1143

\section{Copyrights}

Copyright for this article is retained by the author(s), with first publication rights granted to the journal.

This is an open-access article distributed under the terms and conditions of the Creative Commons Attribution license (http://creativecommons.org/licenses/by/4.0/). 